\title{
Personality Types and Personality Traits in DSM-5: Do They Really Match?*
}

\author{
Sérgio Eduardo Silva de Oliveira ${ }^{1, * *}$ (®), Tiago Cunha de Oliveira ${ }^{2}$ (D, \\ Denise Ruschel Bandeira ${ }^{3}$ (๑), \& Robert Frank Krueger ${ }^{4}$ (1) \\ ${ }^{1}$ Department of Clinical Psychology, University of Brasília, Brasília, DF, Brazil \\ ${ }^{2}$ Department of Basic Psychological Processes, University of Brasilia, Brasilia, DF, Brazil \\ ${ }^{3}$ Department of Development and Personality Psychology, Federal University of Rio Grande do Sul, \\ Porto Alegre, RS, Brazil \\ ${ }^{4}$ Department of Psychology, University of Minnesota, Minneapolis, MN, USA.
}

\begin{abstract}
The alternative model of personality disorders introduced in the fifth edition of the Diagnostic and Statistical Manual of Mental Disorders provides a diagnostic system that is expected to correspond to the well-known categorical approach of personality disorder diagnoses. The current study aims to improve knowledge about the relationship between pathological personality traits and their corresponding personality types. A Brazilian sample of 1,162 people took part in this study. The results point to some level of continuity between the two models when the variables were treated as dimensional. Contrariwise, there is a lack of strong scientific evidence to justify the maintenance of the categorical approach. We recommend the exclusion of the categorical approach from personality disorder diagnosis systems.
\end{abstract}

KEYWORDS: categorical model, dimensional model, personality disorder diagnosis

\section{Tipos e Traços de Personalidade no DSM-5: Eles Realmente Combinam?}

\begin{abstract}
RESUMO - O modelo alternativo de transtornos da personalidade introduzido na quinta edição do Manual Diagnóstico e Estatístico de Transtornos Mentais oferece um sistema diagnóstico que supostamente deve corresponder ao bem conhecido modelo de diagnóstico categórico dos transtornos da personalidade. O presente estudo tem por objetivo incrementar os conhecimentos sobre a relação entre os traços de personalidade e seus correspondentes tipos de personalidade. Uma amostra brasileira de 1.162 pessoas participou deste estudo. Os resultados indicaram algum nível de continuidade entre os dois modelos quando as variáveis foram consideradas dimensionais. Por outro lado, existe uma falta de evidência científica que justifique a manutenção da abordagem categórica. Recomenda-se a exclusão da abordagem categórica de sistemas diagnósticos de transtornos da personalidade.
\end{abstract}

PALAVRAS-CHAVE: modelo categórico, modelo dimensional, diagnóstico de transtorno da personalidade

Psychological constructs, particularly mental disorders, are difficult to define as categorical or dimensional because they are not easily observable as, for instance, weight or height (Borsboom et al., 2016). When it comes to personality, one can detect the historical tradition of categorizing people into certain personality types. This typological approach understands that people can be organized by grouping individuals that share several personality traits into one personality type (Asendorpf \& Denissen, 2006). From the very first edition of the Diagnostic and Statistical Manual of Mental Disorders (DSM-I; American Psychiatric Association, 1952), the diagnosis of personality disorders

* Apoio: CNPq; MCTI/CNPq/MEC/CAPES No 18/2012; CAPES; PDSE-CAPES (number 99999.007135/2014-09).

**Email: sesoliveira@unb.br

— Submetido: 09/10/2019; Revisado: 22/01/2020; Aceito: 26/03/2020 
(PD) also followed this rationale. However, empirical evidence (see Eaton et al., 2011; Haslam et al., 2012) has revealed that the conceptualization of PDs as categorical constructs is poorly scientifically confirmed. The usage of a categorical model produces, for example, high levels of diagnostic overlap and within-groups heterogeneity (Clark, 2007; Skodol et al., 2011; Zanarini et al., 1998).

From this scenario, various dimensional models for personality pathology emerged (see Trull, 2005; Widiger, 2007; Widiger \& Simonsen, 2005). Krueger et al. (2012) presented an empirically-based pathological personality traits model, which comprises 25 facets of pathological personality that fit into five broad domains (Negative Affectivity, Detachment, Antagonism, Disinhibition, and Psychoticism). This pathological personality traits model was included in the fifth edition of the DSM (DSM-5; American Psychiatric Association, 2013) as part of the alternative model of personality disorders (AMPD). In order to facilitate a smooth transition between these models (from categorical to dimensional), the AMPD was built as a hybrid model, which allows clinicians to identify a specific personality type (categorical approach) by matching the patient's profile traits (dimensional approach) with the prototypical profiles of the specific PD types.

This "diplomatic" model has been empirically tested in several studies with different sample characteristics (Anderson et al., 2014; Bach \& Sellbom, 2016; Hopwood et al., 2012; Fossati et al., 2013; Morey et al., 2016; Strickland, 2014; Watters et al., 2019; Yam \& Simms, 2014) and the results have proven to be somewhat controversial. Borderline $\mathrm{PD}$, for example, is the category with the most inconsistent results across studies. It is hard to find a reliable pattern of association between this PD type and its corresponding traits from the dimensional model. Some studies found significant correlations between Borderline PD and unexpected traits (Bach \& Sellbom, 2016; Hopwood et al., 2012; Strickland, 2014; Watters et al., 2019; Yam \& Simms, 2014), and did not find significant or relevant correlations between the same PD and some of its expected traits (Anderson et al., 2014; Bach \& Sellbom, 2016; Hopwood et al., 2012; Morey et al., 2016; Strickland, 2014; Watters et al., 2019; Yam \& Simms, 2014).

The AMPD specifies six PD types: Antisocial PD, Avoidant PD, Borderline PD, Narcissistic PD, ObsessiveCompulsive PD, and Schizotypal PD (American Psychiatric Association, 2013). Various studies have found significant associations between these PDs and most of their expected traits (Anderson et al., 2014; Hopwood et al., 2012; Morey et al., 2016; Strickland, 2014; Watters et al., 2019; Yam \& Simms, 2014). However, there were a few alarming exceptions per study, such as Anderson et al. (2014) failing to find a significant correlation between Antisocial PD and one of its expected traits - Risk Taking - and Hopwood et al. (2012) finding an irrelevant but statistically significant correlation between Avoidant PD and Intimacy Avoidance. Nonetheless, the correlation coefficients are highly diversified among the studies, varying in three core aspects: (1) regarding the expected correlation between specific traits with their corresponding $P D$ - for example, Anderson et al. (2014) did not find a statistically significant correlation between the Restricted Affectivity facet and the Schizotypal PD, while, on other hand, Morey (2016) found this association; (2) regarding the effect size of correlation coefficients - for example, some studies only found low or irrelevant correlation coefficients $(<.30)$ between the PDs that were kept in the AMPD and all of the personality traits (Anderson et al., 2014; Strickland, 2014), while others found many effect sizes above .50 and some above .70 in their studies (Hopwood et al., 2012; Morey et al., 2016; Yam \& Simms, 2014); and (3) regarding the unexpected correlation between some traits and PDs - for example, Hopwood et al. (2014) and Yam and Simms (2014) both found a statistically significant correlation between the Perseveration trait with Borderline PD, while Bach (2016), Anderson et al. (2014), and Morey (2016) failed to do so. In all these studies, for example, Obsessive-Compulsive PD did not significantly correlate with at least half of its expected traits.

Hopwood et al. (2012), Anderson et al. (2014), Strickland (2014), and Morey et al. (2016) also explored the associations between the traits and some of or all of the PDs that were left out of the AMPD. As expected, the results were very much incongruent between the studies. Generally, these results cause us to wonder whether the personality types approach really matches the personality traits one.

Besides that, from all of the studies reviewed, half of them were conducted on non-clinical samples (Anderson et al., 2014; Hopwood et al., 2012; Strickland, 2014) and the other half on clinical samples (Bach \& Sellbom, 2016; Morey et al., 2016; Yam \& Simms, 2016). No research has been made to evaluate the consistency of the AMPD from a comparative perspective, assessing it in community and clinical samples.

Recently, Watters et al. (2019) presented a meta-analytic review of studies involving the association between the PDs maintained in the AMPD and their proposed corresponding facets. Even though discriminant validity was questionable among most parts of the model, the results indicated quite strong convergent validity - with the only exception being Obsessive-Compulsive PD. In other words, the PDs were generally well associated with the proposed traits, but many other non-proposed traits were also correlated to those PDs. Therefore, according to Watters et al. (2019), it does not seem necessary to abandon the hybrid model; instead, it should be adapted in order to improve its discriminant validity.

The current study was designed to improve current knowledge about the relationship between the pathological personality traits and their corresponding PD types. The aforementioned studies achieved quite contradictory results, appearing to indicate the non-match between these approaches, although the authors suggest that there is 
evidence of matching. The meta-analytic review of this issue (Watters et al., 2019) also reported a number of issues, such as the well-known comorbidity among PDs. Consequently, we replicated some analytical methods already described in the literature and included four new analyses: (1) the comparison of the correlation coefficients between two samples, one being comprised of people without indicators of mental health issues and another including people with clinical indicators; (2) the correlation between the PD types according to the conceptualization derived from both DSM5's Sections II and III; (3) the concordance between the two approaches for incorporating people within a diagnostic category; and (4) the incidence of pathological personality traits in homogeneous groups of people with a single PD. These analytical approaches will be better described later.

Although there are several studies related to the object of the current research, the effective correspondence between the categorical and hybrid models remains unclear. Our study aims to contribute to clarifying this issue by providing further empirically based results. We expect that our findings can improve the decision-making process the reviewing in the DSM-5.1.

\section{METHOD}

\section{Participants}

The sample was composed of 1,162 participants, recruited mainly via social media. Their ages varied from 15 to 73 years $(M=29.13, S D=10.16)$. The sample was divided into two groups: community and clinical. To be allocated in the clinical group, participants had to fill at least one of the following criteria: (1) self-reported as having one or more psychiatric diagnosis $(n=196)$; and/ or (2) self-reported as using psychotropic medication $(n=$ 156); and/or (3) presented a moderate suicide risk (score equal or greater than six) on the Suicidality Module of the Mini International Neuropsychiatric Interview (MINI; $n=$ 169); and/or (4) presented a risk of psychiatric disturbance (score equal or greater than eight) on the Self-Reporting Questionnaire (SQR-20) $(n=402)$. Table 1 shows the sample characterization.

\section{Instruments}

Sociodemographic and Health Questionnaire (SHQ): this instrument was composed of a variety of sociodemographic questions such as age, gender, socioeconomic and educational level, marital status, and ethnicity. Moreover, there were several health questions about, for example, psychiatric diagnosis and the use of psychotropic medication.

Suicidality Module of the Mini International Neuropsychiatric Interview (Sheehan et al., 1998): the MINI was originally administered as a structured true or false interview to assess several mental disorders. However, for this study, we solely used the Suicidality Module and transformed it into a self-reported scale. We used the Brazilian Portuguese version adapted by Amorim (2000). The internal consistence coefficient measured by Kuder-Richardson method (KD-20) in the current study was $\mathrm{KD}-20=.78$.
Self-Reporting Questionnaire (SRQ-20; Harding et al., 1980): this is a 'yes' or 'no' response scale composed of 20 items, which contemplate symptoms like anxiety, depression, and psychosomatic illness, being useful for screening common mental disorders. The cut-off point of eight was used in order to divide the sample into clinical and non-clinical groups, as recommended by previous national and international research studies (Harpham, 2003; Mari \& Williams, 1985, 1986; World Health Organization, 1994). The Brazilian version we used was validated by Mari and Williams $(1985,1986)$. In the current study, the SRQ-20 internal consistence coefficient was KD-20 $=.83$.

Structured Clinical Interview for the DSM-IV-TR Axis II Disorders - Personality Questionnaire (SCID-II-PQ; First, Gibbon, Spitzer, Williams, \& Benjamin, 1997): the SCID-II-PQ is a self-reported instrument composed of 119 true-false items, which evaluates the 10 PDs described in DSM-IV-TR (American Psychiatric Association, 2000), as well as passive-aggressive and depressive PDs. The Brazilian version used in this study was adapted by Melo and Rangé (2010); this instrument has consistent evidence of validity and reliability (Anderson et al., 2014; Jacobsberg et al., 1995; Osone \& Takahashi, 2003; Ryder et al., 2007; Warren \& South, 2009). The internal consistence coefficients estimated by KD-20 in the current study ranged from .52 (Obsessive-Compulsive and Schizoid PDs) to .85 (Borderline PD).

Personality Inventory for DSM-5 (PID-5; Krueger et al., 2012): this is a 220-item questionnaire with a four-point Likert type response scale (from 0 "very false or often false" to 3 "very true or often true"). It evaluates the 25 personality traits suggested in Section III of the DSM-5 (American Psychiatric Association, 2013), as well as the five domains that encompass them at a hierarchical level. We used the Brazilian version adapted by Oliveira (2016). The internal consistence coefficients estimated by Cronbach's alpha ranged from .70 (Suspiciousness) to .96 (Eccentricity) in the current study. 
Table 1

Sample characteristics

\begin{tabular}{|c|c|c|c|c|c|c|}
\hline \multirow{2}{*}{$\begin{array}{l}\text { Age } \\
\end{array}$} & \multicolumn{2}{|c|}{ Community } & \multicolumn{2}{|c|}{ Clinical } & \multicolumn{2}{|c|}{ Total } \\
\hline & \multicolumn{2}{|c|}{$(n=592)$} & \multicolumn{2}{|c|}{$(n=570)$} & \multicolumn{2}{|c|}{$(n=1,162)$} \\
\hline - Minimum | Maximum & 15 & 73 & 15 & 64 & 15 & 73 \\
\hline - M (SD) & 30.15 & (11.15) & 28.08 & $(8.90)$ & 29.13 & (10.16) \\
\hline \multicolumn{7}{|l|}{ Gender $-f(\%)$} \\
\hline - Male & 148 & $(25.0)$ & 107 & $(18.8)$ & 255 & (21.9) \\
\hline - Female & 420 & $(71.0)$ & 443 & $(77.7)$ & 863 & $(74.3)$ \\
\hline - Missing & 24 & $(4.1)$ & 20 & (3.5) & 44 & (3.8) \\
\hline \multicolumn{7}{|l|}{ Ethnicity $^{\mathrm{a}}-f(\%)$} \\
\hline - White & 439 & $(74.2)$ & 399 & $(70.0)$ & 838 & $(72.1)$ \\
\hline - Black & 18 & $(3.0)$ & 32 & (5.6) & 50 & (4.3) \\
\hline - Yellow & 5 & $(0.8)$ & 9 & (1.6) & 14 & (1.2) \\
\hline - Indian & 2 & $(0.3)$ & 0 & $(0.0)$ & 2 & $(0.2)$ \\
\hline - Brown (Pardo) & 91 & $(15.4)$ & 101 & $(17.7)$ & 192 & $(16.5)$ \\
\hline - Other & 11 & (1.9) & 9 & (1.6) & 20 & (1.7) \\
\hline - Missing & 26 & $(4.4)$ & 20 & $(3.5)$ & 46 & $(4.0)$ \\
\hline \multicolumn{7}{|l|}{ Marital Status $-f(\%)$} \\
\hline - Single & 193 & $(32.6)$ & 201 & $(35.3)$ & 394 & (33.9) \\
\hline - Single in a relationship & 176 & $(29.7)$ & 181 & $(31.8)$ & 357 & (3.7) \\
\hline - Married & 161 & $(27.2)$ & 142 & $(24.9)$ & 303 & $(26.1)$ \\
\hline - Divorced & 18 & $(3.0)$ & 18 & $(3.2)$ & 36 & $(3.1)$ \\
\hline - Divorced in a relationship & 8 & $(1.4)$ & 9 & (1.6) & 17 & (1.5) \\
\hline - Widower & 3 & $(0.5)$ & 0 & $(0.0)$ & 3 & $(0.3)$ \\
\hline - Widower in a relationship & 1 & $(0.2)$ & 0 & $(0.0)$ & 1 & $(0.1)$ \\
\hline - Other & 3 & $(0.5)$ & 3 & $(0.5)$ & 6 & $(0.5)$ \\
\hline - Missing & 29 & $(4.9)$ & 16 & $(2.8)$ & 45 & (3.9) \\
\hline \multicolumn{7}{|l|}{ Educational Level $-f(\%)$} \\
\hline - Low & 2 & $(0.3)$ & 6 & $(1.1)$ & 8 & $(0.7)$ \\
\hline - Medium & 21 & $(3.6)$ & 43 & (7.5) & 64 & (5.5) \\
\hline - High & 543 & $(91.7)$ & 496 & $(87.0)$ & 1039 & $(89.4)$ \\
\hline - Missing & 26 & $(4.4)$ & 25 & $(4.4)$ & 51 & $(4.4)$ \\
\hline \multicolumn{7}{|l|}{ Socioeconomic level $-f(\%)$} \\
\hline - Low & 6 & $(1.0)$ & 7 & $(1.2)$ & 13 & $(1.1)$ \\
\hline - Medium-Low & 196 & $(33.1)$ & 244 & $(42.8)$ & 440 & $(37.9)$ \\
\hline - Medium & 159 & (26.9) & 140 & $(24.6)$ & 299 & $(25.7)$ \\
\hline - Medium-High & 91 & (15.4) & 74 & $(13.0)$ & 165 & $(14.2)$ \\
\hline - High & 107 & (18.1) & 77 & $(13.5)$ & 184 & (15.8) \\
\hline - Missing & 33 & $(5.6)$ & 28 & $(4.9)$ & 61 & (5.3) \\
\hline
\end{tabular}

Note: ${ }^{\text {a }}$ we used the Brazilian Institute of Geography and Statistics' classification system (see https://en.wikipedia.org/wiki/Race_and_ethnicity_in_Brazil)

\section{Procedures}

This research was submitted and approved by the Ethics Committee of the Psychology Institute of the Federal University of Rio Grande do Sul (registration number CAAE 31610114.9.0000.5334). In order to execute the data collection, a website was developed and its platform announced via social media, email lists, and lectures. The target population for the survey comprised university students, community groups, and, to ensure that people under clinical conditions would be included, we also announced it in support groups for different kinds of mental illnesses - e.g. schizophrenia, social phobia, depression, anxiety, bipolar disorders, and borderline personality disorder. We 
also counted on a snowball sampling procedure (Goodman, 1961). First, the participants provided informed consent. Then, they registered on the online platform - this part of the procedure was encrypted, which ensured both anonymity and privacy. After completing all questionnaires, the subjects would have access to a PDF performance report; this was a strategy used to motivate participants to complete the questionnaires.

\section{Data Analysis}

First, to test if specific pathological personality traits are related with their corresponding PD types, we performed Pearson's correlation analyses. Our interest in this bivariate approach is to examine if the traits that were proposed to belong to specific PD types are really correlated. Considering the mono-method bias (Donaldson \& Grant-Vallone, 2002), correlations equal or greater to .30 were considered significant. Pearson's correlation analyses were conducted separately for each sample (community and clinical), with the aim of exploring the nature of these correlations for each group. Fisher's r-to-z transformation was conducted to measure the sample difference between the strength of these correlations.

We subsequently examined the association between the PD types conforming to the conceptualization of the DSM-5's Sections II and III. Therefore, PDs according to Section II were defined by the sum of the amount of positively endorsed items for each PD type, while PDs in Section III were defined by the arithmetic average of the obtained scores in all facets proposed to a specific diagnostic category. For this investigation, we performed Pearson's correlation analyses. To be considered as corresponding, it was expected that the highest effect sizes of the correlation coefficients were between the same PD conceptualizations. In other words, for example, the correlation coefficient between Borderline PD (SCID-II-PQ) and Borderline PD (PID-5) was expected to have the largest effect size in relation to effect sizes of correlation coefficients with other PDs.

Next, to further investigate the association of specific pathological personality traits with their corresponding PD types, we conducted several hierarchical linear regression analyses. Our objective was to identify the extent to which the proposed pathological personality traits explained their corresponding PD types. For this purpose, we followed two analytical strategies: (1) we regressed the PD constructs onto their proposed pathological personality traits as one block, followed by all of the non-proposed traits in the subsequent block; and (2) we removed all non-proposed traits that did not show significant correlation (i.e. $\geq .30$ ) with the construct from the second block. To verify the improvements in the explained variance, we exchanged the variables in the blocks (the first block with the non-proposed traits and the second block with the proposed traits). The matching between types and traits approaches would be confirmed if the expected traits for each PD type explained the variance of their corresponding PD and no other trait would explain that variation.

We also aimed to test the diagnostic concordance between the two approaches (Sections II and III). To do so, we used kappa statistic. The cut-off points for the diagnostic decisions were established as follows: (1) for the Section II approach, we ranked the community sample in 100 equal parts in relation to the summed score for each PD type, and we used the $95^{\text {th }}$ percentile as the cut-off point. This conservative cut-off point was chosen based on the balance between two major items of information: (a) the literature, which indicates the prevalence of around $14 \%$ of PDs in community samples (Grant et al., 2004; Torgersen et al., 2001) and (b) by considering that the SCID-II-PQ has a very low specificity (Ekselius et al., 1994); (2) for the Section III approach, we calculated the $T$ score $(M=50, S D=10)$, considering the mean and standard-deviation values from the community sample. The cut-off point was a $T$ score equal to or greater than 65 (one and a half standard-deviations above the mean). To compute the diagnostic categories for retained PDs in the AMPD, we followed the proposed DSM-5 algorithm (American Psychiatric Association, 2013). For the removed PDs, we used the Hopwood et al. (2012) algorithm with some changes, in order to maintain the same pattern of the retained disorders: for those PDs composed of two or three traits (Passive-Aggressive, Depressive, Dependent, and Histrionic), all of them should be present (i.e., $T$ score $\geq 65$ ) for positivity of the diagnostic category; for a Paranoid PD diagnosis, three out of four traits should be present, one of them being Suspiciousness; for a Schizoid PD diagnosis, three out of four traits should be present, one of them being Intimacy Avoidance. These two traits (Suspiciousness and Intimacy Avoidance) were chosen based on the core features of the two corresponding PDs. In order to obtain corresponding validity evidence between the two approaches, we expected Kappa's coefficients to be greater than .80 , i.e., a percentage of agreement higher than $64 \%$ (McHugh, 2012).

Finally, we searched our dataset for people who presented a percentile score equal to or higher than the $95^{\text {th }}$ percentile in only one PD type (operationalized via SCID-II-PQ). This was in order to analyze the pattern of pathological personality traits present in each PD type without their comorbidity with other PDs interfering, which seems to influence the results of research about the AMPD (Watters et al., 2019). We found 227 (19.5\%) people from the total sample that presented with high scores in a single PD. Then, once the subsamples were too small, varying from 4 to 36 people among PD types, we qualitatively analyzed the percentage of the presence of the DSM-5's pathological personality traits $(T \geq 65)$ within each PD 
group. Our objective was to verify if the expected traits for each PD would present themselves at a pathological level in a homogeneous group of people with a high level of a single specific PD (in the absence of comorbidity with other PDs). In order to determine the matching between the two approaches, we expected to find the presence of at least $70 \%$ of the pathological personality traits for each PD. We also expected $100 \%$ Anxiousness traits to be present in the Avoidant PD group, as well as Grandiosity and Attention Seeking traits in the Narcissistic PD group, and the Rigid Perfectionism trait in the Obsessive-Compulsive PD group. This expectation of $100 \%$ is based on the AMPD diagnostic system, which indicates that those traits must be present for the diagnosis of these PD categories.

\section{RESULTS}

Our first interest was to verify if the expected traits for each PD would present correlation coefficients with statistical significance $(p$-value $\leq .05)$ and clinical relevance $(r \geq .30)$. Table 2 demonstrates zero-order correlation coefficients between the SCID-II-PQ PDs' summed scores and the PID-5 facets and domains scores for community and clinical samples separately. As can be seen in Table 2, three out of six DSM-5 retained PDs did not present clinically relevant correlation coefficients with one or two expected traits. This happened with Avoidant PD and the Intimacy Avoidance trait, Borderline PD and the Risk Taking trait, and Obsessive-Compulsive PD and the Restricted Affectivity and Intimacy Avoidance traits. The weak correlation coefficient between Borderline PD and the Risk Taking trait is the most alarming result, because the AMPD system denotes that the Risk Taking trait is one of the required traits in diagnosing Borderline PD (see American Psychiatric Association, 2013).

In Table 2, it is also possible to observe many clinically relevant correlation coefficients between PDs and nonexpected pathological personality traits. We highlight the correlations between the Perceptual Dysregulation trait and Borderline PD, and between the Deceitfulness trait and Narcissistic PD. Regarding the other PDs removed from the AMPD, we can observe the same pattern of correlation with the non-expected traits.

After running a Fischer's r-to-z transformation, it was possible to identify statistically significant differences in the correlation coefficients between both of the samples (see underlined values in Table 2). Although the direction of the associations remained the same across samples, the correlation strengths changed. Correlation coefficients tended to be higher in the community sample than in the clinical sample for Antisocial PD and Passive-Aggressive PD. The opposite occurred in Borderline PD, Schizotypal PD, Schizoid PD, Histrionic PD, and Depressive PD. There were no differences in the correlation sizes between samples in Narcissistic PD and Obsessive-Compulsive PD. Correlation strengths did not present a coherent pattern in Avoidant PD, Dependent PD, and Paranoid PD (higher values were identified in both clinical and community samples). The differences observed between samples regarding the correlation coefficients' effect size did not show any relevant information that should be considered for statistical controlling. However, a closer look at these differences may provide some interesting knowledge about the mental functioning of people with and without mental health issues relating to personality pathology. For example, the biggest difference found in this study was for the correlation between the Depressivity trait and Borderline PD; the clinical group $(r=.63)$ presented a much higher correlation coefficient than the community group $(r=.46$; $\Delta r=.17)$, indicating that other pathological features may strengthen this relationship.

Since Sections II and III of the DSM-5 have different conceptualizations for the same PD types, we also aimed to understand how well they are associated. The results are shown in Table 3. Borderline PD, Narcissistic PD, Schizotypal PD, Schizoid PD, Dependent PD, and Depressive PD presented a good match among the two paradigms in both samples. The clinical sample also presented a good match between the conceptualizations of Histrionic PD. Fischer's r-to-z transformation indicated that Antisocial PD, Avoidant PD, Obsessive-Compulsive PD, and Passive-Aggressive PD have presented higher correlation coefficients in the community sample than in the clinical sample. Borderline PD, Schizotypal PD, Schizoid PD, Histrionic PD, and Depressive PD, on the other hand, tended to follow the opposite trend. Besides that, Narcissistic PD, Paranoid PD, and Dependent PD did not show any differences in correlation coefficient sizes between the two subsamples.

In order to comprehensively evaluate the association of specific and non-specific traits with PD types, we performed a set of hierarchical regression analyses. We were particularly interested in verifying whether the proposed traits would explain the variance of their corresponding PDs above and beyond the non-proposed traits. Table 4 displays our main findings. 
Correlation coefficients for PID-5 traits and SCID-II-PQ scales for community (Co) and clinical (Cl) samples

\begin{tabular}{|c|c|c|c|c|c|c|c|c|c|c|c|c|c|c|c|c|c|c|c|c|c|c|c|c|}
\hline & \multicolumn{12}{|c|}{ Retained personality disorders } & \multicolumn{8}{|c|}{ Removed personality disorders } & \multicolumn{4}{|c|}{ Other personality disorders } \\
\hline & \multicolumn{2}{|c|}{ Antisocial } & \multicolumn{2}{|c|}{ Avoidant } & \multicolumn{2}{|c|}{ Borderline } & \multicolumn{2}{|c|}{ Narcissistic } & \multicolumn{2}{|c|}{ Obs.-Comp. } & \multicolumn{2}{|c|}{ Schizotypal } & \multicolumn{2}{|c|}{ Paranoid } & \multicolumn{2}{|c|}{ Schizoid } & \multicolumn{2}{|c|}{ Histrionic } & \multicolumn{2}{|c|}{ Dependent } & \multicolumn{2}{|c|}{ Pa.-Aggres. } & \multicolumn{2}{|c|}{ Depressive } \\
\hline & Co & $\mathbf{C l}$ & Co & $\mathrm{Cl}$ & Co & $\mathbf{C l}$ & Co & $\mathbf{C l}$ & Co & $\mathbf{C l}$ & Co & $\mathbf{C l}$ & Co & $\mathbf{C l}$ & Co & $\mathbf{C l}$ & Co & $\mathbf{C l}$ & Co & $\mathbf{C l}$ & Co & $\mathbf{C l}$ & Co & $\mathbf{C l}$ \\
\hline ANHE & .12 & .16 & $\underline{.47}^{\mathrm{a}}$ & $\underline{.55}^{\mathrm{a}}$ & .40 & .50 & .28 & .30 & .25 & .18 & .31 & .41 & .31 & .37 & $\underline{.41}^{\mathrm{a}}$ & $\underline{.50}^{\mathrm{a}}$ & -.04 & -.02 & .23 & .26 & .43 & .45 & $\underline{.56}^{\mathrm{a}}$ & $\underline{.66}^{\mathrm{a}}$ \\
\hline ANXI & .10 & .06 & $.41^{\mathrm{a}}$ & $.43^{\mathrm{a}}$ & $\underline{.43}^{\mathrm{a}}$ & $\underline{.53}^{\mathrm{a}}$ & .34 & .32 & .31 & .23 & .39 & .47 & .38 & .42 & .09 & .24 & .20 & .21 & $.39^{\mathrm{a}}$ & $.46^{\mathrm{a}}$ & .43 & .41 & $.58^{\mathrm{a}}$ & $.60^{\mathrm{a}}$ \\
\hline ATT-S & .32 & .19 & .07 & -.05 & .33 & .34 & $.5^{\mathrm{a}}$ & $.56^{a}$ & .19 & .18 & .30 & .27 & .28 & .25 & .00 & -.07 & $\underline{.56}^{\mathrm{a}}$ &.$^{.67^{a}}$ & .26 & .26 & .35 & .25 & .23 & .15 \\
\hline CALL & $.42^{\mathrm{a}}$ & $.39^{\mathrm{a}}$ & .20 & .18 & .47 & .47 & .56 & .58 & .18 & .25 & .34 & .40 & .45 & .42 & .31 & .32 & .17 & .23 & .09 & .03 & .40 & .36 & .32 & .31 \\
\hline DECE & $.47^{\mathrm{a}}$ & $.39^{\mathrm{a}}$ & .21 & .19 & .47 & .47 & .56 & .62 & .16 & .18 & .34 & .41 & .39 & .40 & .18 & .16 & .41 & .45 & .24 & .23 & .43 & .39 & .30 & .32 \\
\hline DEPR & .14 & .23 & .43 & .51 & $\underline{.46}^{\mathrm{a}}$ &.$^{.63^{a}}$ & .30 & .35 & .17 & .15 & .35 & .47 & .31 & .43 & .29 & .39 & .06 & .11 & .30 & .38 & $.46^{\mathrm{a}}$ & $.45^{\mathrm{a}}$ &.$^{.64^{a}}$ & $\underline{.71}^{\mathrm{a}}$ \\
\hline DIST & .14 & .19 & .31 & .35 & .40 & .51 & .26 & .29 & .11 & .09 & .27 & .36 & .23 & .30 & .16 & .26 & .18 & .23 & .31 & .37 & .42 & .40 & .36 & .44 \\
\hline ECCE & .34 & .25 & .18 & .26 & .47 & .55 & .42 & .43 & .25 & .22 & $.52^{\mathrm{a}}$ & $.57^{\mathrm{a}}$ & .39 & .39 & .26 & .34 & .17 & .24 & .14 & .17 & .43 & .37 & .33 & .35 \\
\hline EMO-L & .17 & .13 & .23 & .28 & $\underline{.51}^{\mathrm{a}}$ &.$^{.65^{a}}$ & .29 & .32 & .22 & .18 & .42 & .48 & .35 & .42 & .05 & .20 & $.27^{\mathrm{a}}$ & $.32^{\mathrm{a}}$ & .36 & .44 & .39 & .39 & .37 & .46 \\
\hline GRAN & .32 & .21 & .09 & .04 & .34 & .35 & $.60^{\mathrm{a}}$ & $.63^{\mathrm{a}}$ & .37 & .30 & .39 & .41 & .35 & .34 & .19 & .18 & .29 & .41 & .10 & .07 & .34 & .36 & .22 & .18 \\
\hline HOST & $.34^{\mathrm{a}}$ & $.32^{\mathrm{a}}$ & .25 & .22 & $.58^{\mathrm{a}}$ & $.62^{\mathrm{a}}$ & .53 & .54 & .30 & .35 & .40 & .47 & $.56^{\mathrm{a}}$ & $.56^{\mathrm{a}}$ & .19 & .29 & .25 & .32 & .20 & .20 & $.52^{\mathrm{a}}$ & $.52^{\mathrm{a}}$ & .38 & .42 \\
\hline IMPU & $.34^{a}$ & $.30^{\mathrm{a}}$ & .13 & .13 & $.58^{\mathrm{a}}$ & $.62^{\mathrm{a}}$ & .34 & .38 & .10 & .11 & .30 & .37 & .32 & .36 & .10 & .13 & .32 & .35 & .28 & .34 & .38 & .37 & .29 & .32 \\
\hline INT-A & .12 & .13 & $.27^{\mathrm{a}}$ & $.29^{\mathrm{a}}$ & .15 & .25 & .18 & .20 & $.13^{\mathrm{a}}$ & $.17^{\mathrm{a}}$ & .22 & .29 & .21 & .24 &. $\mathbf{4 3}^{\mathrm{a}}$ & $.41^{\mathrm{a}}$ & -.04 & .02 & .01 & -.05 & .17 & .18 & .20 & .26 \\
\hline IRRE & $.42^{\mathrm{a}}$ & ${\underline{.32^{\mathrm{a}}}}^{-1}$ & .25 & .25 & .47 & .54 & .45 & .41 & .09 & .02 & .38 & .39 & .35 & .30 & .18 & .20 & .28 & .27 & .28 & .27 & .46 & .46 & .25 & .35 \\
\hline MANI & $.40^{\mathrm{a}}$ &. $\mathbf{3 3}^{\mathrm{a}}$ & .07 & -.04 & .39 & .37 & .51 & .55 & .23 & .23 & .35 & .31 & .32 & .29 & .09 & .07 &. $\mathbf{4 3}^{\mathrm{a}}$ &. $\mathbf{5 0}^{\mathrm{a}}$ & .15 & .11 & .31 & .27 & .18 & .16 \\
\hline PER-D & .33 & .33 & .25 & .24 & .57 & .64 & .45 & .50 & .27 & .24 & $.61^{a}$ & $.64^{\mathrm{a}}$ & .43 & .43 & .21 & .28 & .25 & .34 & .25 & .29 & .46 & .46 & .37 & .43 \\
\hline PERS & .22 & .17 & .35 & .38 & .47 & .50 & .40 & .38 & $.39^{\mathrm{a}}$ & $.3^{a}$ & .44 & .46 & .35 & .39 & .23 & .22 & .16 & .30 & .32 & .37 & .46 & .37 & .42 & .45 \\
\hline RES-A & .22 & .19 & .39 & .28 & .27 & .30 & .32 & .35 & $.22^{\mathrm{a}}$ & $.19^{\mathrm{a}}$ & $.31^{a}$ & $.30^{\mathrm{a}}$ & .33 & .27 &. $\mathbf{4 3}^{\mathrm{a}}$ & $.40^{\mathrm{a}}$ & -.02 & .04 & .05 & -.02 & .29 & .24 & .32 & .24 \\
\hline RIG-P & .15 & .01 & .21 & .16 & .26 & .23 & .34 & .29 & $.57^{\mathrm{a}}$ & $.51^{\mathrm{a}}$ & .42 & .33 & .36 & .31 & .19 & .17 & .05 & .14 & .18 & .07 & .26 & .19 & .28 & .24 \\
\hline RIS-T & $.34^{\mathrm{a}}$ & $.25^{\mathrm{a}}$ & -.12 & -.20 & $.26^{\mathrm{a}}$ & $.24^{\mathrm{a}}$ & .20 & .26 & .04 & -.01 & .22 & .13 & .18 & .06 & -.01 & -.02 & .26 & .28 & .02 & -.01 & .15 & .13 & .00 & -.02 \\
\hline SEP-I & .14 & .08 & .28 & .22 & $.37^{\mathrm{a}}$ & $.43^{\mathrm{a}}$ & .34 & .35 & .13 & .05 & .27 & .33 & .29 & .30 & .01 & .00 & .23 & .32 & $.5^{a}$ & $.59^{a}$ & .38 & .23 & .37 & .40 \\
\hline SUBM & .10 & .06 & .36 & .35 & .29 & .29 & .28 & .19 & .18 & .09 & .25 & .22 & .18 & .20 & .09 & .09 & .18 & .23 & $.40^{\mathrm{a}}$ & $.41^{\mathrm{a}}$ & .31 & .18 & .33 & .36 \\
\hline SUSP & .31 & .23 & .31 & .32 & .49 & .58 & .53 & .52 & .28 & .29 & $.59^{a}$ & $.62^{\mathrm{a}}$ & $.62^{\mathrm{a}}$ & $.66^{\mathrm{a}}$ & .31 & .33 & .23 & .24 & .30 & .26 & .47 & .47 & .44 & .52 \\
\hline U-B-E & .34 & .29 & .08 & .10 & .44 & .46 & .43 & .41 & .29 & .23 & $.69^{a}$ & $.65^{\mathrm{a}}$ & $.37^{a}$ & $.35^{\mathrm{a}}$ & .18 & .27 & .22 & .25 & .15 & .12 & .38 & .35 & .23 & .25 \\
\hline WITH & .19 & .17 & $.54^{a}$ & $.56^{\mathrm{a}}$ & .33 & .45 & .36 & .28 & .28 & .20 & $\underline{.39}^{\mathrm{a}}$ &. $.47^{\mathrm{a}}$ & .39 & .43 & $.52^{\mathrm{a}}$ & $.53^{\mathrm{a}}$ & -.10 & -.10 & .17 & .09 & .34 & .32 & .44 & .48 \\
\hline NEG-A & .23 & .19 & .40 & .43 & .61 & .70 & .49 & .46 & .32 & .25 & .51 & .57 & .49 & .55 & .12 & .23 & .31 & .36 & .53 & .57 & .57 & .49 & .58 & .66 \\
\hline DETA & .25 & .25 & .54 & .56 & .45 & .60 & .44 & .44 & .30 & .26 & .48 & .56 & .48 & .52 & .55 & .57 & .01 & .06 & .21 & .20 & .47 & .47 & .56 & .64 \\
\hline
\end{tabular}




\begin{tabular}{|c|c|c|c|c|c|c|c|c|c|c|c|c|c|c|c|c|c|c|c|c|c|c|c|c|}
\hline & \multicolumn{12}{|c|}{ Retained personality disorders } & \multicolumn{8}{|c|}{ Removed personality disorders } & \multicolumn{4}{|c|}{ Other personality disorders } \\
\hline & \multicolumn{2}{|c|}{ Antisocial } & \multicolumn{2}{|c|}{ Avoidant } & \multicolumn{2}{|c|}{ Borderline } & \multicolumn{2}{|c|}{ Narcissistic } & \multicolumn{2}{|c|}{ Obs.-Comp. } & \multicolumn{2}{|c|}{ Schizotypal } & \multicolumn{2}{|c|}{ Paranoid } & \multicolumn{2}{|c|}{ Schizoid } & \multicolumn{2}{|c|}{ Histrionic } & \multicolumn{2}{|c|}{ Dependent } & \multicolumn{2}{|c|}{ Pa.-Aggres. } & \multicolumn{2}{|c|}{ Depressive } \\
\hline & Co & $\mathbf{C l}$ & Co & $\mathbf{C l}$ & Co & $\mathbf{C l}$ & Co & Cl & Co & Cl & Co & Cl & Co & Cl & Co & $\mathbf{C l}$ & Co & Cl & Co & Cl & Co & Cl & Co & Cl \\
\hline ANTA & .48 & .38 & .18 & .10 & .55 & .56 & .71 & .74 & .32 & .32 & .46 & .48 & $.50^{\mathrm{a}}$ & $.48^{\mathrm{a}}$ & .19 & .19 & .49 & .57 & .23 & .20 & .50 & .46 & .34 & .32 \\
\hline DISI & .35 & .34 & .12 & .14 & .49 & .56 & .28 & .33 & -.13 & -.10 & .22 & .30 & .22 & .24 & .07 & .14 & .33 & .32 & .24 & .31 & .38 & .38 & .21 & .29 \\
\hline PSYC & .39 & .32 & .19 & .23 & .56 & .61 & .50 & .49 & .31 & .25 & .69 & .68 & .46 & .43 & .26 & .34 & .23 & .30 & .20 & .21 & .48 & .43 & .35 & .38 \\
\hline
\end{tabular}

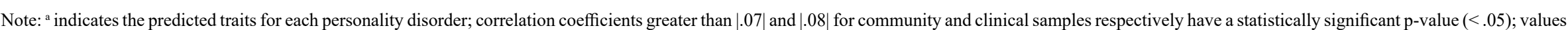

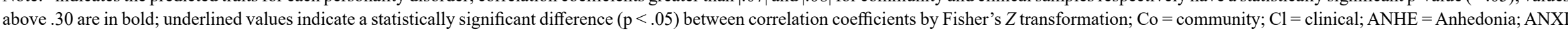

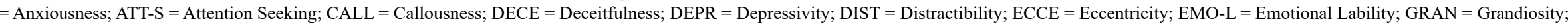

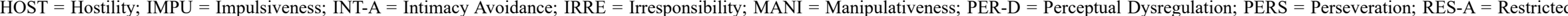

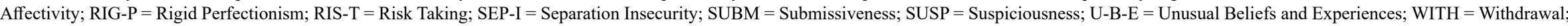
NEG-A = Negative Affectivity; DETA = Detachment; ANTA = Antagonism; DISI = Disinhibition; PSYC = Psychoticism.

Table 3

Correlation coefficients for personality disorder types according to DSM-IV and DSM-5 conceptualizations

\begin{tabular}{|c|c|c|c|c|c|c|c|c|c|c|c|c|c|c|c|c|c|c|c|c|c|c|c|c|}
\hline \multirow{4}{*}{ DSM-5 } & \multicolumn{24}{|c|}{ DSM-IV } \\
\hline & \multicolumn{12}{|c|}{ Retained personality disorders } & \multicolumn{8}{|c|}{ Removed personality disorders } & \multicolumn{4}{|c|}{ Other personality disorders } \\
\hline & \multicolumn{2}{|c|}{ ASPD } & \multicolumn{2}{|c|}{ APD } & \multicolumn{2}{|c|}{ BPD } & \multicolumn{2}{|c|}{ NPD } & \multicolumn{2}{|c|}{ OCPD } & \multicolumn{2}{|c|}{ STPD } & \multicolumn{2}{|c|}{ PPD } & \multicolumn{2}{|c|}{ SPD } & \multicolumn{2}{|c|}{ HPD } & \multicolumn{2}{|c|}{ DPD } & \multicolumn{2}{|c|}{ PAPD } & \multicolumn{2}{|c|}{ DEPPD } \\
\hline & Co & $\mathbf{C l}$ & Co & $\mathbf{C l}$ & Co & $\mathrm{Cl}$ & Co & $\mathrm{Cl}$ & Co & $\mathbf{C l}$ & Co & $\mathrm{Cl}$ & Co & $\mathbf{C l}$ & Co & $\mathbf{C l}$ & Co & $\mathbf{C l}$ & Co & $\mathrm{Cl}$ & Co & $\mathrm{Cl}$ & Co & $\mathbf{C l}$ \\
\hline ASPD & .54 & .46 & .19 & .14 & .66 & .68 & .63 & .66 & .23 & .23 & .47 & .50 & .52 & .49 & .20 & .22 & .45 & .49 & .26 & .25 & .53 & .50 & .35 & .38 \\
\hline APD & .18 & .17 & .58 & .61 & .45 & .57 & .40 & .36 & .33 & .26 & .49 & .54 & .44 & .48 & .49 & .56 & .01 & .03 & .28 & .25 & .47 & .45 & .61 & .66 \\
\hline BPD & .34 & .28 & .35 & .35 & .71 & .79 & .51 & .53 & .28 & .22 & .52 & .58 & .53 & .54 & .14 & .26 & .37 & .40 & .47 & .52 & .59 & .53 & .57 & .62 \\
\hline NPD & .36 & .22 & .09 & -.01 & .39 & .39 & .64 & .67 & .31 & .27 & .39 & .38 & .35 & .33 & .10 & .05 & .49 & .62 & .22 & .20 & .39 & .38 & .26 & .19 \\
\hline OCPD & .25 & .18 & .43 & .39 & .40 & .44 & .44 & .43 & .47 & .43 & .49 & .49 & .44 & .43 & .46 & .43 & .05 & .17 & .19 & .12 & .41 & .34 & .43 & .41 \\
\hline STPD & .38 & .37 & .41 & .40 & .56 & .64 & .55 & .53 & .35 & .30 & .67 & .69 & .56 & .55 & .45 & .48 & .14 & .20 & .22 & .19 & .52 & .47 & .48 & .49 \\
\hline PPD & .40 & .33 & .34 & .33 & .60 & .66 & .60 & .57 & .36 & .36 & .67 & .68 & .64 & .63 & .41 & .45 & .23 & .28 & .23 & .18 & .55 & .52 & .45 & .50 \\
\hline SPD & .21 & .21 & .51 & .54 & .35 & .48 & .36 & .36 & .27 & .24 & .38 & .47 & .39 & .42 & .56 & .59 & -.06 & -.02 & .13 & .09 & .38 & .38 & .47 & .52 \\
\hline HPD & .39 & .28 & .16 & .08 & .53 & .59 & .58 & .62 & .27 & .26 & .46 & .46 & .41 & .42 & .06 & .09 & .55 & .64 & .33 & .35 & .45 & .39 & .34 & .34 \\
\hline DPD & .14 & .08 & .45 & .42 & .46 & .52 & .41 & .37 & .26 & .15 & .39 & .43 & .36 & .38 & .08 & .13 & .26 & .33 & .57 & .63 & .48 & .35 & .55 & .57 \\
\hline PAPD & .32 & .32 & .39 & .43 & .65 & .73 & .53 & .53 & .30 & .28 & .47 & .55 & .56 & .58 & .28 & .40 & .22 & .25 & .29 & .35 & .61 & .57 & .59 & .67 \\
\hline DEPPD & .14 & .18 & .53 & .58 & .52 & .64 & .38 & .38 & .31 & .21 & .43 & .52 & .41 & .47 & .30 & .44 & .10 & .12 & .38 & .43 & .53 & .51 & .71 & .76 \\
\hline
\end{tabular}

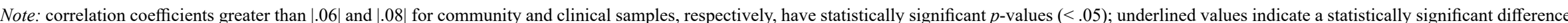

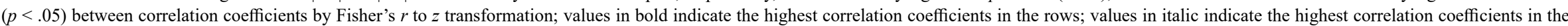

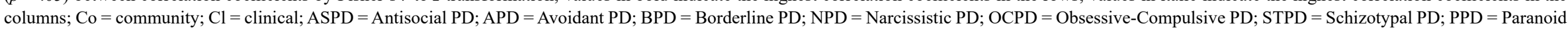
PD; SPD = Schizoid PD; HPD = Histrionic PD; DPD = Dependent PD; PAPD = Passive-Aggressive PD; DEPPD = Depressive PD. 
By analyzing Model 1 in Table 4, it is possible to see that all of the non-specified traits provided information significantly beyond that previously specified about the PDs - except for Antisocial and Paranoid PDs in the community sample. However, it is vital to highlight three PDs - Avoidant, Narcissistic, and Passive-Aggressive - that can be better predicted by their non-specified traits than their specified ones.

The results obtained from Model 2 indicated a similar pattern. The majority of the correlated traits provided significant incremental information. The exceptions were for Antisocial and Paranoid PDs in the community sample, Histrionic PD in the clinical sample, and Schizoid PD in both samples. Narcissistic and Passive-Aggressive PDs should be the ones kept in mind in this model. Their variances were better explained by their correlated traits than by the traits that were expected of them.

We also aimed to verify the correspondence between both of the diagnosis methods. For that, kappa statistic was used.
The negative and positive diagnostics from each of the two models (categorical and alternative), as well as the predictive values (negative and positive) and Kappa coefficients for each PD can be observed in Table 5.

All Kappa coefficients presented $p$-values lower than .001. However, the effect size of these coefficients ranged from .15 (Obsessive-Compulsive PD) to .56 (Borderline PD), which represents minimal (between 4\% and 15\%) and weak (from $15 \%$ to $35 \%$ ) agreement, respectively (McHugh, 2012). The correspondence found in the current study was mostly due to the high agreement among the negative cases (true negatives). By examining the predictive values in Table 5, one can conclude that the positive cases were generally much lower than the negative ones. Thus, it can be seen that the positive cases of diagnosis that matched between the models were quite infrequent. The one exception to this was Avoidant PD, whose positive and negative predictive values came closer to each other.

Table 4

DSM-5 specified traits and non-proposed traits regressed on DSM-IV criterion counts

\begin{tabular}{|c|c|c|c|c|c|c|c|c|c|c|c|c|}
\hline \multirow{4}{*}{$\begin{array}{l}\text { Personality } \\
\text { Disorders }\end{array}$} & \multicolumn{6}{|c|}{ Model 1} & \multicolumn{6}{|c|}{ Model 2} \\
\hline & \multirow{2}{*}{\multicolumn{2}{|c|}{$R^{2}$}} & \multicolumn{4}{|c|}{$\Delta R^{2}$} & \multirow{2}{*}{\multicolumn{2}{|c|}{$R^{2}$}} & \multicolumn{4}{|c|}{$\Delta R^{2}$} \\
\hline & & & \multicolumn{2}{|c|}{$\begin{array}{l}\text { Specified } \\
\text { traits }\end{array}$} & \multicolumn{2}{|c|}{$\begin{array}{c}\text { Non-specified } \\
\text { traits }\end{array}$} & & & \multicolumn{2}{|c|}{$\begin{array}{l}\text { Specified } \\
\text { traits }\end{array}$} & \multicolumn{2}{|c|}{$\begin{array}{c}\text { Other correlated } \\
\text { traits }\end{array}$} \\
\hline & Co & Cl & Co & $\mathrm{Cl}$ & Co & $\mathrm{Cl}$ & Co & Cl & Co & $\mathrm{Cl}$ & Co & $\mathrm{Cl}$ \\
\hline \multicolumn{13}{|l|}{ Retained } \\
\hline Antisocial & .34 & .27 & $.12^{\mathrm{c}}$ & $.11^{\mathrm{c}}$ & .03 & $.05^{\mathrm{b}}$ & .32 & .25 & $.13^{c}$ & $.13^{\mathrm{c}}$ & .01 & $.03^{\mathrm{c}}$ \\
\hline Avoidant & .45 & .49 & $.07^{\mathrm{c}}$ & $.07^{\mathrm{c}}$ & $.08^{\mathrm{c}}$ & $.08^{\mathrm{c}}$ & .40 & .44 & $.10^{\mathrm{c}}$ & $.12^{\mathrm{c}}$ & $.03^{\mathrm{b}}$ & $.04^{\mathrm{c}}$ \\
\hline Borderline & .61 & .70 & $.12^{\mathrm{c}}$ & $.12^{\mathrm{c}}$ & $.06^{\mathrm{c}}$ & $.05^{\mathrm{c}}$ & .60 & .70 & $.12^{\mathrm{c}}$ & $.12^{\mathrm{c}}$ & $.06^{\mathrm{c}}$ & $.04^{\mathrm{c}}$ \\
\hline Narcissistic & .58 & .61 & $.06^{\mathrm{c}}$ & $.06^{\mathrm{c}}$ & $.16^{\mathrm{c}}$ & $.16^{\mathrm{c}}$ & .58 & .61 & $.06^{\mathrm{c}}$ & $.06^{\mathrm{c}}$ & $.16^{\mathrm{c}}$ & $.15^{\mathrm{c}}$ \\
\hline Ob.- Comp. & .39 & .33 & $.12^{\mathrm{c}}$ & $.12^{\mathrm{c}}$ & $.06^{\mathrm{c}}$ & $.06^{\mathrm{c}}$ & .35 & .30 & $.15^{\mathrm{c}}$ & $.15^{\mathrm{c}}$ & $.01^{\mathrm{a}}$ & $.03^{\mathrm{c}}$ \\
\hline Schizotypal & .63 & .61 & $.23^{\mathrm{c}}$ & $.17^{\mathrm{c}}$ & $.03^{\mathrm{b}}$ & $.02^{\mathrm{a}}$ & .63 & .61 & $.25^{\mathrm{c}}$ & $.18^{\mathrm{c}}$ & $.03^{\mathrm{c}}$ & $.02^{\mathrm{b}}$ \\
\hline \multicolumn{13}{|l|}{ Removed } \\
\hline Paranoid & .51 & .52 & $.11^{\mathrm{c}}$ & $.13^{\mathrm{c}}$ & .03 & $.03^{\mathrm{a}}$ & .51 & .51 & $.11^{\mathrm{c}}$ & $.13^{\mathrm{c}}$ & .02 & $.03^{\mathrm{a}}$ \\
\hline Schizoid & .37 & .41 & $.14^{\mathrm{c}}$ & $.10^{\mathrm{c}}$ & $.04^{\mathrm{a}}$ & $.05^{\mathrm{c}}$ & .34 & .36 & $.18^{c}$ & $.16^{\mathrm{c}}$ & .01 & .01 \\
\hline Histrionic & .41 & .54 & $.09^{\mathrm{c}}$ & $.09^{\mathrm{c}}$ & $.08^{\mathrm{c}}$ & $.07^{\mathrm{c}}$ & .37 & .48 & $.14^{c}$ & $.19^{\mathrm{c}}$ & $.04^{\mathrm{c}}$ & .01 \\
\hline Dependent & .40 & .47 & $.13^{\mathrm{c}}$ & $.10^{\mathrm{c}}$ & $.05^{\mathrm{b}}$ & $.06^{\mathrm{c}}$ & .37 & .44 & $.16^{c}$ & $.17^{\mathrm{c}}$ & $.02^{\mathrm{a}}$ & $.02^{\mathrm{b}}$ \\
\hline Pas.-Aggr. & .48 & .46 & $.03^{\mathrm{c}}$ & $.03^{\mathrm{c}}$ & $.11^{\mathrm{c}}$ & $.14^{\mathrm{c}}$ & .47 & .46 & $.03^{\mathrm{c}}$ & $.03^{\mathrm{c}}$ & $.11^{\mathrm{c}}$ & $.13^{\mathrm{c}}$ \\
\hline Depressive & .55 & .61 & $.16^{\mathrm{c}}$ & $.14^{\mathrm{c}}$ & $.03^{\mathrm{b}}$ & $.03^{\mathrm{c}}$ & .54 & .61 & $.17^{\mathrm{c}}$ & $.15^{\mathrm{c}}$ & $.03^{\mathrm{b}}$ & $.03^{\mathrm{c}}$ \\
\hline
\end{tabular}

Note: ${ }^{\mathrm{a}} p<.05 ;{ }^{\mathrm{b}} p<.01 ;{ }^{\mathrm{c}} p<.001 ; \mathrm{Co}=$ community; $\mathrm{Cl}=$ clinical. 
Correspondence between diagnostic classification based on DSM-IV and DSM-5 paradigms

\begin{tabular}{|c|c|c|c|c|c|c|c|c|}
\hline & & & \multicolumn{2}{|c|}{$\begin{array}{l}\text { Categorical Model } \\
\text { (DSM-IV) }\end{array}$} & \multicolumn{2}{|c|}{ Predictive Value } & \multicolumn{2}{|c|}{ Correspondence } \\
\hline & & & Negative & Positive & Negative & Positive & Kappa & $p$-value \\
\hline \multirow{24}{*}{ 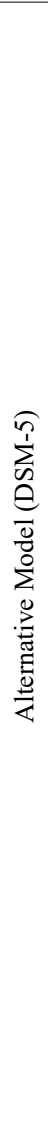 } & \multirow{2}{*}{ Antisocial } & Negative & 1049 & 88 & \multirow{2}{*}{98.96} & \multirow{2}{*}{13.73} & \multirow{2}{*}{.193} & \multirow{2}{*}{$<.001$} \\
\hline & & Positive & 11 & 14 & & & & \\
\hline & \multirow{2}{*}{ Avoidant } & Negative & 735 & 72 & \multirow{2}{*}{77.29} & \multirow{2}{*}{65.88} & \multirow{2}{*}{.341} & \multirow{2}{*}{$<.001$} \\
\hline & & Positive & 216 & 139 & & & & \\
\hline & \multirow{2}{*}{ Borderline } & Negative & 960 & 86 & \multirow{2}{*}{97.36} & \multirow{2}{*}{51.14} & \multirow{2}{*}{.564} & \multirow{2}{*}{$<.001$} \\
\hline & & Positive & 26 & 90 & & & & \\
\hline & \multirow{2}{*}{ Narcissistic } & Negative & 1016 & 71 & \multirow{2}{*}{97.32} & \multirow{2}{*}{39.83} & \multirow{2}{*}{.443} & \multirow{2}{*}{$<.001$} \\
\hline & & Positive & 28 & 47 & & & & \\
\hline & \multirow{2}{*}{ Obsessive-Compulsive } & Negative & 1020 & 103 & \multirow{2}{*}{97.70} & \multirow{2}{*}{12.71} & \multirow{2}{*}{.148} & \multirow{2}{*}{$<.001$} \\
\hline & & Positive & 24 & 15 & & & & \\
\hline & \multirow{2}{*}{ Schizotypal } & Negative & 1020 & 59 & \multirow{2}{*}{96.68} & \multirow{2}{*}{44.86} & $46 ?$ & $<001$ \\
\hline & & Positive & 35 & 48 & & & .462 & $<.001$ \\
\hline & Paranoid & Negative & 968 & 141 & 0978 & 52 & 200 & -001 \\
\hline & raranoia & Positive & 12 & 41 & 98.18 & 22.33 & 299 & $<.001$ \\
\hline & Schizoid & Negative & 963 & 129 & 0737 & 2543 & 302 & $<001$ \\
\hline & STIIIEUTU & Positive & 26 & 44 & (37.07 & 25.45 & .302 & -.001 \\
\hline & Hictrioni & Negative & 1061 & 75 & 0870 & 77 & 200 & 01 \\
\hline & 1115tilomic & Positive & 13 & 13 & 98.19 & $14 . / 1$ & .200 & $<.001$ \\
\hline & Denendent & Negative & 948 & 166 & 0875 & 1782 & 237 & $<001$ \\
\hline & 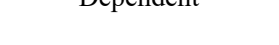 & Positive & 12 & 36 & 30.10 & 11.02 & (25) & -.001 \\
\hline & Paccive A roreccive & Negative & 857 & 194 & 0728 & 30.06 & 356 & 001 \\
\hline & rassive-Aggiessive & Positive & 24 & 87 & 91.20 & 50.90 & . & -.001 \\
\hline & Denrecsive & Negative & 878 & 149 & 0723 & 4247 & 470 & 001 \\
\hline & & Positive & 25 & 110 & & & & \\
\hline
\end{tabular}

Finally, we qualitatively examined the percentage of the presence of the DSM-5's pathological personality traits within homogeneous groups of people with high levels of a single PD. Table 6 shows the results of this analysis. Although we have a very small sample size for each group, the results generally outline a failure of correspondence between the two models for PD diagnoses. Only three pathological personality traits showed a percentage of presence greater than 50\% (Depressivity and Impulsivity traits for Borderline PD; and Unusual
Beliefs \& Experiences for Schizotypal PD). The other three pathological personality traits were not observed $(0 \%$ presence) in their expected PDs (Anxiousness for Borderline PD; Intimacy Avoidance for ObsessiveCompulsive PD; and Suspiciousness for Schizotypal $\mathrm{PD})$. The traits that are required for some PD diagnoses, that should be present in $100 \%$ of cases, were also not observed. For example, Grandiosity and Attention Seeking traits were present in only $50 \%$ of cases instead of $100 \%$ as expected. 
Percentage of people with high DSM-5 facet and domain T scores (> 65) regarding indication of a single type of personality disorder

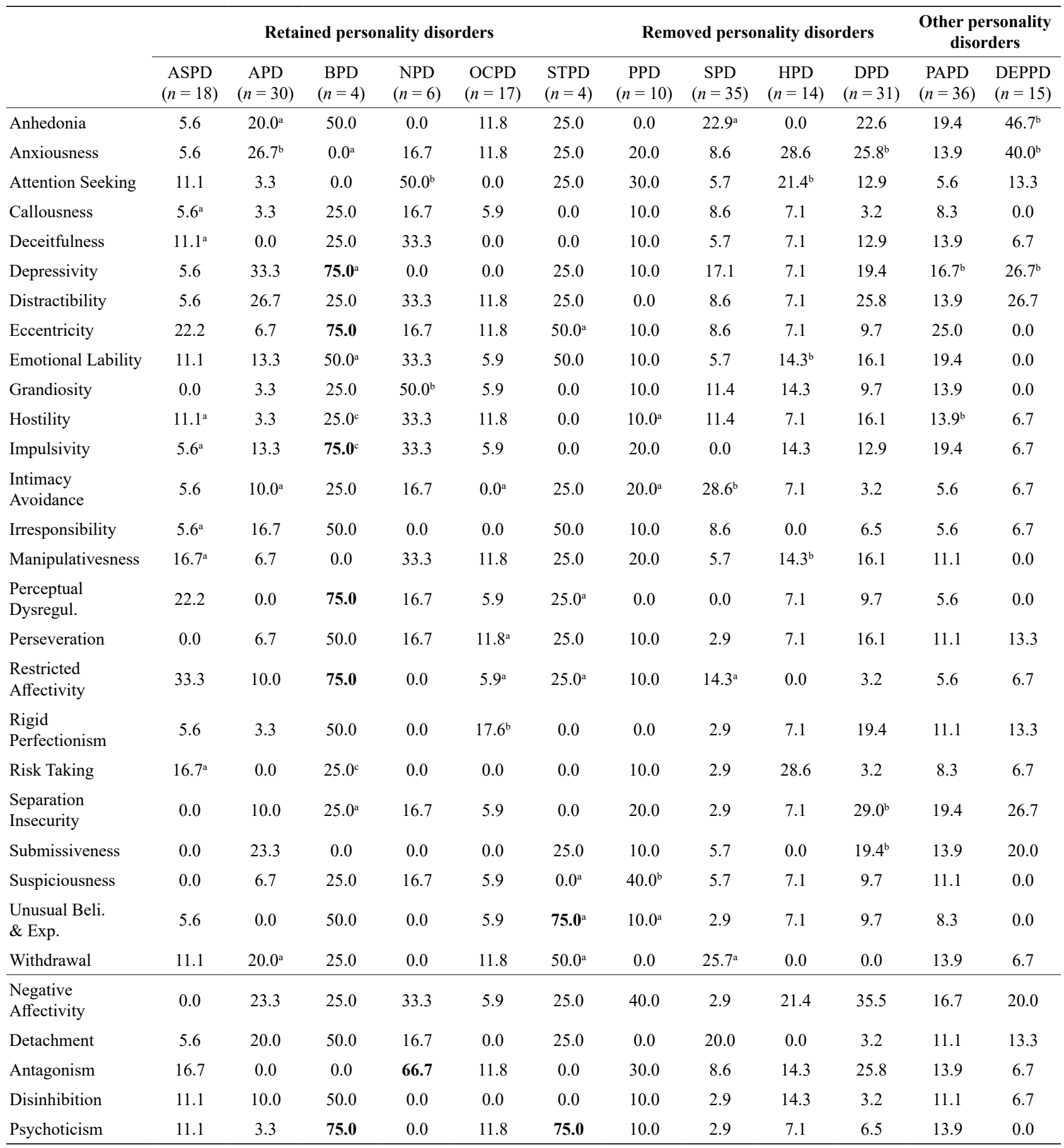

Note: ${ }^{a}$ indicates an expected trait; ${ }^{\mathrm{b}}$ indicates a required traits for the diagnosis; ${ }^{\mathrm{c}}$ indicates the traits of which at least one must be present for the diagnosis; values above 50\% are in bold; ASPD = Antisocial PD; APD = Avoidant PD; BPD = Borderline PD; NPD = Narcissistic PD; OCPD = Obsessive-Compulsive PD; STPD = Schizotypal PD; PPD = Paranoid PD; SPD = Schizoid PD; HPD = Histrionic PD; DPD = Dependent PD; PAPD = Passive-Aggressive PD; DEPPD = Depressive PD. 


\section{DISCUSSION}

The main goal of this study was to increase our knowledge about the relationship between the categorical and dimensional models of personality pathology. From our obtained results, there was a certain continuity between them, which could support the AMPD. However, the differences we found could generate considerable clinical implications, which would indicate the abandonment of the categorical approach in AMPD.

The associations between the PDs and their expected traits were generally consistent. For most of the cases, these correlations were at least statistically significant. Borderline PD, Narcissistic PD, and Schizotypal PD were the PD types that presented the most adequate correlation pattern with their specified traits. Our results were similar to the results found by Yam and Simms (2014) and Watters et al. (2019) for Borderline PD, by Hopwood et al. (2012) for Schizotypal PD, and by Hopwood et al. (2012), Morey et al. (2016), and Watters et al. (2019) for Narcissistic PD. Although these similarities are apparent, our results also differed from those obtained in other studies (Anderson et al. 2014; Bach \& Sellbom, 2016; Strickland, 2014). These differences could point to the difficulty of establishing a reliable correspondence between PD types and traits. Thus, clinicians must pay thorough attention to the paradigm they are using to describe people's personality. Using a categorical approach, for example, does not mean that the expected traits will be present. Furthermore, in contrast to Watters et al.'s (2019) recommendation of adjusting the traits specified for each PD in order to increase AMPD discriminant validity, we would suggest abandoning the categorical approach of AMPD. The dimensional model of PDs proposed for the ICD-11 excludes the categories of different kinds of PDs and operates on a dimensional description of severity levels (which are categorical, but regarding the same dimension and not independent elements) and trait qualifiers (Bach \& First, 2018; Tyrer et al., 2019). The dimensional approach has already proved to be more valid (e.g., Hunter-Reel et al., 2014; Markon et al., 2011), reliable (Haslam et al., 2012; Markon et al., 2011), and useful (e.g., Morey et al., 2014) than the categorical model.

The variations in PD levels are not exclusively accounted for by their specific traits. According to our hierarchical linear regression analyses, significant percentages of the variances of all of the PDs were accounted for by their specified traits. However, non-specified traits provided significant incremental information for the variation of personality types in the majority of cases. We highlight Narcissistic and Passive-Aggressive PDs, for which non-specified traits provided a higher level of incremental information than specified traits. These results were wholly congruent to Hopwood et al. (2012). Similarly, Morey et al. (2016) found that Avoidant PD had more of its variance accounted for by non-specified traits than by the ones expected. These results weaken the AMPD, as one can argue that other traits (beyond the specified ones) can be involved with the PDs. In clinical practice, it does not make much sense to only evaluate the PDs via assessing their expected traits. Numerous other pathological personality traits might affect an individual's personality functioning. AMPD provides the category of Personality Disorder - Trait Specified in order to describe pathological personality profiles that do not match any prototypical one (American Psychiatric Association, 2013), and so is useful in describing any pathological personality profile outliers (Clark et al., 2015).

Our main findings related to the poor correspondence between the models, as displayed in Tables 5 and 6 . Morey and Skodol (2013) empirically analyzed the diagnostic rules for each PD of AMPD based on the DSM-IV-TR system. The Kappa statistics they found were lower than .60, i.e., less than 35\% agreement according to McHugh (2012). Our Kappa statistics were also lower than .60. These results underscore the low reliability between categorical models (Haslam et al., 2012; Markon et al., 2011). In order to go further, we dealt with the comorbidity issue, which seems to be a factor that somewhat confuses the results (Watters et al., 2019), and we sought to observe the presence of the traits expected for each PD in groups of people with a high level of a single PD. Within groups of participants with high levels of a single PD trait, we did not find a desirable percentage (i.e., $>70 \%$ ) of the presence of the expected traits. Although we had a very small sample in some groups, the pattern of inconsistency between the paradigms was observed even in those groups with 30 or more people. Based on these results, it is possible to propose that the comorbidity seems not to be the factor that unsettles the correspondence between approaches. 


\section{CONCLUSION}

The current study aimed to investigate how well the categorical and dimensional paradigms for PD conceptualization would correspond. Our results showed that there is some continuity between the traditional way of diagnosing PD and the AMPD. However, some findings of the current study, and also from previous research, indicate that the categorical approach is not a comprehensive way of describing people's personality pathology. Although the AMPD presents several advances in terms of describing personality pathology, it also regresses when proposing a categorical outcome. We believe that there is not enough scientific evidence, nor clinical need, to justify maintaining the categorical approach.

Some limitations of this study must be highlighted. This includes the mono method approach that was used, which tends to inflate the correlations. The lack of clinically diagnosed participants through standard assessment tools could also influence the results. Thus, further research should be conducted to better clarify the correspondence between the categorical and dimensional models of personality pathology.
Our results demonstrated that, in general, pathological personality traits are related to the symptom level of their predicted PD type. However, a few exceptions were observed and some of them demand the model review, for example, the lack of correlation between Borderline PD and Risk Taking. We also observed a lack of discriminant validity due to a large number of correlations between unexpected traits and symptom levels of PD types. The most alarming result is regarding the Narcissistic PD which had its variance explained mainly by the unexpected traits.

The most fragile element of the AMPD is its categorical outcome. Our results indicated that the two approaches (Section II and III) tend to provide different outcomes to a person. In other words, an individual will probably be included in two different diagnostic categories depending on the model used for his/her assessment. Thus, our results indicate the lack of continuity between the two paradigms, mainly due to the categorical outcome, and we suggest the exclusion of the categorical outcome from the AMPD.

\section{ACKNOWLEDGEMENTS}

This research was supported by grants from the National Council for Scientific and Technological Development (CNPq; MCTI/CNPq/MEC/CAPES No 18/2012). The opinions expressed are solely those of the authors and not necessarily those of the funding source. SESO was financially supported by Coordination for the Improvement of Higher Education Personnel (CAPES) and PDSE-CAPES (number 99999.007135/2014-09).

\section{REFERENCES}

American Psychiatric Association. (1952). Diagnostic and statistical manual of mental disorders. American Psychiatric Association.

American Psychiatric Association. (2000). Diagnostic and statistical manual of mental disorders, Fourth Edition, Text Revision (DSM-IV-TR). American Psychiatric Association.

American Psychiatric Association. (2013). Diagnostic and statistical manual of mental disorders (5th ed.). American Psychiatric Association.

Amorim, P. (2000). Mini International Neuropsychiatric Interview (MINI): Validação de entrevista breve para diagnóstico de transtornos mentais. Revista Brasileira de Psiquiatria, 22(3), 106-115. https://doi.org/10.1590/S1516-44462000000300003

Anderson, J., Snider, S., Sellbom, M., Krueger, R., \& Hopwood, C. (2014). A comparison of the DSM-5 section II and section III personality disorder structures. Psychiatry Research, 216(3), 363-372. https://doi.org/10.1016/j.psychres.2014.01.007

Asendorpf, J., \& Denissen, J. J. A. (2006). Predictive validity of personality types versus personality dimensions from early childhood to adulthood: Implications for the distinction between core and surface traits. Merrill-Palmer Quarterly, 52(3), 486-513. https://doi.org/10.1353/mpq.2006.0022
Bach, B., \& First, M. B. (2018). Application of the ICD-11 classification of personality disorders. BMC Psychiatry, 18(1), 351. https://doi.org/10.1186/s12888-018-1908-3

Bach, B., \& Sellbom, M. (2016). Continuity between DSM-5 categorical criteria and traits criteria for borderline personality disorder. The Canadian Journal of Psychiatry, 61(8), 489-494. https://doi.org/10.1177/0706743716640756

Borsboom, D., Rhemtulla, M., Cramer, A. O. J., van der Maas, H. L. J., Scheffer, M., \& Dolan, C. V. (2016). Kinds versus continua: A review of psychometric approaches to uncover the structure of psychiatric constructs. Psychological Medicine, 46(8), 15671579. https://doi.org/10.1017/S0033291715001944

Clark, L. A. (2007). Assessment and diagnosis of personality disorder: Perennial issues and an emerging reconceptualization. Annual Review of Psychology, 58(1), 227-257. https://doi. org/10.1146/annurev.psych.57.102904.190200

Clark, L. A., Vanderbleek, E. N., Shapiro, J. L., Nuzum, H., Allen, X., Daly, E., Kingsbury, T. J., Oiler, M., \& Ro, E. (2015). The brave new world of personality disorder-trait specified: Effects of additional definitions on coverage, prevalence, and comorbidity. Psychopathology Review, 2(1), 52-82. https://doi. org/10.5127/pr.036314 
Donaldson, S. I., \& Grant-Vallone, E. J. (2002). Understanding self-report bias in organizational behavior research. Journal of Business and Psychology, 17(2), 245-260. https://doi. org/10.1023/A:1019637632584

Eaton, N. R., Krueger, R. F., South, S. C., Simms, L. J., \& Clark, L. A. (2011). Contrasting prototypes and dimensions in the classification of personality pathology: Evidence that dimensions, but not prototypes, are robust. Psychological Medicine, 41(6), 1151-1163. https://doi.org/10.1017/ S0033291710001650

Ekselius, L., Lindström, E., Knorring, L. V., Bodlund, O., \& Kullgren, G. (1994). SCID II interviews and the SCID Screen questionnaire as diagnostic tools for personality disorders in DSM-III-R. Acta Psychiatrica Scandinavica, 90(2), 120-123. https://doi.org/10.1111/j.1600-0447.1994.tb01566.x

First, M. B., Gibbon, M., Spitzer, R. L., Williams, J. B. W., \& Benjamin, L. S. (1997). SCID-II personality questionnaire. American Psychiatric Press.

Fossati, A., Krueger, R. F., Markon, K. E., Borroni, S., \& Maffei, C. (2013). Reliability and validity of the personality inventory for DSM-5 (PID-5): Predicting DSM-IV personality disorders and psychopathy in community-dwelling Italian adults. Assessment, 20(6), 689-708. https://doi.org/10.1177/1073191113504984

Goodman, L. A. (1961). "Snowball sampling." Annals of Mathematical Statistic, 32(1), 148-170. https://www.jstor. org/stable/2237615

Grant, B. F., Hasin, D. S., Stinson, F. S., Dawson, D. A., Chou, S. P., Ruan, W. J., \& Pickering, R. P. (2004). Prevalence, correlates, and disability of personality disorders in the United States: Results from the national epidemiologic survey on alcohol and related conditions. The Journal of Clinical Psychiatry, 65(7), 948-958. https://doi.org/10.4088/JCP.v65n0711

Harding, T. W., De Arango, V., Baltazar, J., Climent, C. E., Ibrahim, H. H. A., Ladrido-Ignacio, L., \& Wig, N. N. (1980). Mental disorders in primary health care: A study of their frequency and diagnosis in four developing countries. Psychological Medicine, 10(2), 231-241. https://doi.org/10.1017/S0033291700043993

Harpham, T. (2003). Measuring mental health in a cost-effective manner. Health Policy and Planning, 18(3), 344-349. https:// doi.org/10.1093/heapol/czg041

Haslam, N., Holland, E., \& Kuppens, P. (2012). Categories versus dimensions in personality and psychopathology: A quantitative review of taxometric research. Psychological Medicine, 42(5), 903-920. https://doi.org/10.1017/S0033291711001966

Hopwood, C. J., Thomas, K. M., Markon, K. E., Wright, A. G., \& Krueger, R. F. (2012). DSM-5 personality traits and DSM-IV personality disorders. Journal of Abnormal Psychology, 121(2), 424-432. https://doi.org/10.1037/a0026656

Hunter-Reel, D., Epstein, E. E., McCrady, B., \& Eddie, D. (2014). Personality disorders and the prediction of alcohol use outcomes for women: Dimensional versus categorical classification. Addiction Research \& Theory, 22(2), 176-180. https://doi.org/10.3109/16066359.2013.793314

Jacobsberg, L., Perry, S., \& Frances, A. (1995). Diagnostic agreement between the SCID-II Screening Questionnaire and the Personality Disorder Examination. Journal of Personality Assessment, 65(3), 428-433. https://doi.org/10.1207/ s15327752jpa6503_4

Krueger, R. F., Derringer, J., Markon, K. E., Watson, D., \& Skodol, A. E. (2012). Initial construction of a maladaptive personality trait model and inventory for DSM-5. Psychological Medicine, 42(9), 1879-1890. https://doi.org/10.1017/ S0033291711002674

Mari, J. J., \& Williams, P. (1985). A comparison of the validity of two psychiatric screening questionnaires (GHQ-12 and SRQ20) in Brazil, using Relative Operating Characteristic (ROC) analysis. Psychological Medicine, 15(03), 651-659. https://doi. org/10.1017/S0033291700031500
Mari, J. J., \& Williams, P. (1986). A validity study of a psychiatric screening questionnaire (SRQ-20) in primary care in the city of Sao Paulo. The British Journal of Psychiatry, 148(1), 23-26. https://doi.org/10.1192/bjp.148.1.23

Markon, K. E., Chmielewski, M., \& Miller, C. J. (2011). The reliability and validity of discrete and continuous measures of psychopathology: A quantitative review. Psychological Bulletin, 137(5), 856-879. http://dx.doi.org/10.1037/a0023678

McHugh, M. L. (2012). Interrater reliability: the kappa statistic. Biochemia Medica, 22(3), 276-282. https://hrcak.srce.hr/89395

Melo, N. M. M., \& Rangé, B. P. (2010, September). SCID-IIDSM-IV - Entrevista clínica estruturada para transtornos de personalidade: Tradução e utilização na DPA/IP/UFRJ. [SCIDII-DSM-IV - structured clinical interview for personality disorders: Translation and use at DPA/IP/UFRJ]. Anais da $8^{\mathrm{a}}$ Mostra de Terapia Cognitivo-Comportamental, 67.

Morey, L. C., Benson, K. T., \& Skodol, A. E. (2016). Relating DSM-5 section III personality traits to section II personality disorder diagnoses. Psychological Medicine, 46(3), 647-655. https://doi.org/10.1017/S0033291715002226

Morey, L. C., \& Skodol, A. E. (2013). Convergence between DSMIV-TR and DSM-5 diagnostic models for personality disorder: Evaluation of strategies for establishing diagnostic thresholds. Journal of Psychiatric Practice, 19(3), 179-193. https://doi. org/10.1097/01.pra.0000430502.78833.06

Morey, L. C., Skodol, A. E., \& Oldham, J. M. (2014). Clinician judgments of clinical utility: A comparison of DSM-IV-TR personality disorders and the alternative model for DSM-5 personality disorders. Journal of Abnormal Psychology, 123(2), 398-405. http://dx.doi.org/10.1037/a0036481

Oliveira, S. E. S. (2016). Structural and dimensional personality evaluation: Psychometric studies and clinical utility [Unpublished doctoral dissertation]. SABI UFRGS. https:// sabi.ufrgs.br/F/J8L4NCUGQHX798769YG9427PTL3R8 C3HMXKSQDKYGJQVKLKVB1-42242? func=full-setset\&set_number $=005570 \&$ set entry $=000024 \&$ format $=999$

Osone, A., \& Takahashi, S. (2003). Twelve month test-retest reliability of a Japanese version of the Structured Clinical Interview for DSM-IV Personality Disorders. Psychiatry and Clinical Neurosciences, 57(5), 532-538. https://doi. org/10.1046/j.1440-1819.2003.01159.x

Ryder, A. G., Costa, P. T., \& Bagby, R. M. (2007). Evaluation of the SCID-II personality disorder traits for DSM-IV: Coherence, discrimination, relations with general personality traits, and functional impairment. Journal of Personality Disorders, 21(6), 626-637. https://doi.org/10.1521/pedi.2007.21.6.626

Sheehan, D., Lecrubier, Y., Sheehan, K. H., Amorim, P., Janavs, J., Weiller, E. H. T., Hergueta, T., Baker, R., \& Dunbar, G. C. L. (1998). The Mini-International Neuropsychiatric Interview (MINI): The development and validation of a structured diagnostic psychiatric interview for DSM-IV and ICD-10. Journal of Clinical Psychiatry, 59(Suppl 20), 22-33. https:// psycnet.apa.org/record/1998-03251-004

Skodol, A. E., Bender, D. S., Morey, L. C., Clark, L. A., Oldham, J. M., Alarcon, R. D., Krueger, R. F., Verheul, R., Bell, C. C., \& Siever, L. J. (2011). Personality disorder types proposed for DSM-5. Journal of Personality Disorders, 25(2), 136-169. https://doi.org/10.1521/pedi.2011.25.2.136

Strickland, C. M. (2014). Validating the Personality Inventory for DSM-5: A trait-based model of personality disorders [Master's thesis]. Florida State University Libraries. https://diginole.lib. fsu.edu/islandora/object/fsu:252895/datastream/PDF/view

Torgersen, S., Kringlen, E., \& Cramer, V. (2001). The prevalence of personality disorders in a community sample. Archives of General Psychiatry, 58(6), 590-596. https://doi.org/10.1001/ archpsyc.58.6.590 
Trull, T. J. (2005). Dimensional models of personality disorder: Coverage and cutoffs. Journal of Personality Disorders, 19(3), 262-282. https://doi.org/10.1521/pedi.2005.19.3.262

Tyrer, P., Mulder, R., Kim, Y. R., \& Crawford, M. J. (2019). The development of the ICD-11 classification of personality disorders: An amalgam of science, pragmatism, and politics. Annual Review of Clinical Psychology, 15, 481-502. https:// doi.org/10.1146/annurev-clinpsy-050718-095736

Warren, J. I., \& South, S. C. (2009). A symptom level examination of the relationship between Cluster B personality disorders and patterns of criminality and violence in women. International Journal of Law and Psychiatry, 32(1), 10-17. https://doi. org/10.1016/j.ijlp.2008.11.005

Watters, C. A., Bagby, R. M., \& Sellbom, M. (2019). Metaanalysis to derive an empirically based set of personality facet criteria for the alternative DSM-5 model for personality disorders. Personality Disorders: Theory, Research, and Treatment, 10(2), 97-104. http://dx.doi.org/10.1037/ per0000307
Widiger, T. A. (2007). Dimensional models of personality disorder. World Psychiatry, 6(2), 79-83. https://pubmed.ncbi.nlm.nih. gov/18235857/

Widiger, T. A., \& Simonsen, E. (2005). Alternative dimensional models of personality disorder: Finding a common ground. Journal of Personality Disorders, 19(2), 110-130. https://doi. org/10.1521/pedi.19.2.110.62628

World Health Organization. (1994). A user's guide to the selfreporting questionnaire (SRQ). World Health Organization.

Yam, W. H., \& Simms, L. J. (2014). Comparing criterion- and trait-based personality disorder diagnoses in DSM-5. Journal of Abnormal Psychology, 123(4), 802-808. https://doi. org/10.1037/a0037633

Zanarini, M. C., Frankenburg, F. R., Dubo, E. D., Sickel, A. E., Trikha, A., Levin, A., \& Reynolds, V. (1998). Axis I Comorbidity of Borderline Personality Disorder. American Journal of Psychiatry, 155(12), 1733-1739. https://doi. org/10.1176/ajp.155.12.1733 